\title{
Optimizing the thermal treatment for restoration of brittle archaeological silver artifacts
}

\author{
Shengyu Liu', Zhuopeng Li ${ }^{1}$, Yihang Zhou ${ }^{1}$, Ruixuan $\mathrm{Li}^{1}$, Zhenda $\mathrm{Xie}^{2}$, Chudong $\mathrm{Liu}^{3}$, Gang Hu${ }^{1 *}$ and \\ Dongbo Hu${ }^{1 *}$
}

\begin{abstract}
Archaeological silver artifacts are often found to be brittle because of long-term corrosion. However, the restoration of brittle archaeological silver artifacts by thermal treatment has never been quantitatively and systematically studied due to the lack of sufficient experimental samples. Herein, the simulated Ag-Cu alloy flake samples with intergranular corrosion consistent with those brittle archaeological silver artifacts were prepared through two-step annealing and accelerated aging in $\mathrm{Fe}\left(\mathrm{NO}_{3}\right)_{3}+\mathrm{AgNO}_{3}$ solution. The changes in the microstructure and mechanical strength $\left(\sigma_{\mathrm{bb}}\right.$ $E_{b}$, and $H V$ ) of the brittle samples after thermal treatments were studied with the help of SEM-EDS, metallographic observation, three-point bending tests, and microhardness tests. In addition, the most suitable conditions for the restoration of the brittle samples were summarized by the temperature-time (T-t) map obtained from a series of comprehensive thermal treatments. Moreover, the differences in microstructures and mechanical strength between the brittle samples annealed in an aerobic/anaerobic environment were revealed. This work provides an important reference for the restoration and conservation of brittle archaeological silver artifacts.
\end{abstract}

Keywords: Embrittlement, Archaeological silver artifacts, Thermal treatment, Conservation, Intergranular corrosion

\section{Introduction}

Silver, because of its excellent ductility, malleability and aesthetic appearance, has been widely used in the production of ancient artifacts [1]. However, due to longterm corrosion [2], some archaeological silver artifacts or, strictly speaking, silver-copper alloys are found to be brittle [2-7]. Some researchers have studied the embrittlement mechanism of archaeological silver artifacts from different angles [1, 8-10], and the general opinion is that embrittlement is mainly caused by intergranular corrosion (local galvanic attack) between the Ag-enriched matrix ( $\alpha$ phase) and the $\mathrm{Cu}$-enriched grain boundary ( $\beta$ phase) $[10,11]$. Other researchers have mainly studied

\footnotetext{
*Correspondence: hugang@pku.edu.cn; hudongbo@pku.edu.cn

${ }^{1}$ The International Center for Chinese Heritage and Archaeology, School of Archaeology and Museology, Peking University, Beijing 100871, China Full list of author information is available at the end of the article
}

the corrosion inhibition [12-18] and seal protection [1921] of silver artifacts, focusing on materials (e.g., perfluoroalkyl amideethanethiol, fluoroalkylthiol, alkylthiol, etc.) and their mechanisms. It is worth noting that very few researchers have mentioned the restoration method of brittle archaeological silver artifacts through thermal treatment $[1,11]$.

Thermal treatment is indeed a common and effective method for the restoration of brittle archaeological silver artifacts at present, regardless of the conservation concept controversy that it might bring about. In the case of the conservation and restoration of brittle silver artifacts that we have been involved in, such as the restoration project of brittle silver artifacts excavated from the Tusi Cemetery of the Yang Family at Xinpu Town, Guizhou Province [22, 23], and the restoration project of brittle silver artifacts collected by Jinhua Museum, Zhejiang Province [24], the restorers usually used a

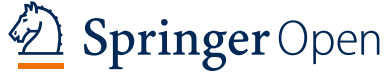

(c) The Author(s) 2022. Open Access This article is licensed under a Creative Commons Attribution 4.0 International License, which permits use, sharing, adaptation, distribution and reproduction in any medium or format, as long as you give appropriate credit to the original author(s) and the source, provide a link to the Creative Commons licence, and indicate if changes were made. The images or other third party material in this article are included in the article's Creative Commons licence, unless indicated otherwise in a credit line to the material. If material is not included in the article's Creative Commons licence and your intended use is not permitted by statutory regulation or exceeds the permitted use, you will need to obtain permission directly from the copyright holder. To view a copy of this licence, visit http://creativecommons.org/licenses/by/4.0/. The Creative Commons Public Domain Dedication waiver (http://creativeco mmons.org/publicdomain/zero/1.0/) applies to the data made available in this article, unless otherwise stated in a credit line to the data. 
high-temperature torch to directly anneal the surface of the silver fragments to reduce embrittlement and restore their mechanical strength and bending resistance. Although this approach has been found to be effective in terms of restoration results, our preliminary research has shown that such a thermal treatment method (by hightemperature torch) may lead to some subsequent potential problems (Additional file 1: Fig. S1). In addition, this method is overly dependent on the restorer's personal skills and experience, and its restoration performance is not very stable. In the long run, allowing actual restoration to be far ahead of scientific research may lead to more serious problems. Therefore, we need to conduct systematic and quantitative research on the mechanisms and effects of thermal treatment to understand its advantages and disadvantages and then optimize the method on this basis to make it safer, more practical and easier to promote. Unfortunately, due to the lack of sufficient experimental materials for quantitative study, no systematic research has been carried out thus far.

In our former work [10], a simulated silver-copper alloy sample with a microstructure similar to that of archaeological silver artifacts was prepared through two-step annealing. Benefitting from this, standardized silvercopper alloy flake samples with an uncorroded $\beta$ phase can be obtained for our study. Subsequently, brittle flake samples with intergranular corrosion were prepared through accelerated aging, which allowed us to have sufficient experimental materials for quantitative study. A three-point bending test [25-30] and microhardness test [31-36], which are considered simple, fast and accurate testing methods for the performance of sheet metal, were carried out to study the changes in the microstructures and mechanical strength of the samples after thermal treatments at different temperatures. Moreover, we designed a series of comprehensive thermal treatments with different temperatures and durations to study the optimal thermal treatment conditions for the restoration of brittle silver artifacts and studied the effect of thermal treatment on the microstructures and mechanical strength of brittle samples under both aerobic and anaerobic conditions.

\section{Experimental}

\section{Chemicals and materials}

Silver (99.99\%) was purchased from Hunan Dongguyunshang Co., Ltd, China. Copper (99.99\%) was purchased from Beijing Feifanshangshi Culture and Arts Co., Ltd, China. Potassium nitrate $\left(\mathrm{KNO}_{3}\right)$, iron (III) sulfate $\left(\mathrm{Fe}_{2}\left(\mathrm{SO}_{4}\right)_{3}\right)$, ammonium ferric sulfate dodecahydrate $\left(\mathrm{NH}_{4} \mathrm{Fe}\left(\mathrm{SO}_{4}\right)_{2} \cdot 12 \mathrm{H}_{2} \mathrm{O}\right)$, iron (II) sulfate heptahydrate $\left(\mathrm{FeSO}_{4} \cdot 7 \mathrm{H}_{2} \mathrm{O}\right)$, silver nitrate $\left(\mathrm{AgNO}_{3}\right)$ and iron (III) nitrate nonahydrate $\left(\mathrm{Fe}\left(\mathrm{NO}_{3}\right)_{3} \cdot 9 \mathrm{H}_{2} \mathrm{O}\right)$ were analytical reagents and purchased from Shanghai Meryer Chemical Technology Co., Ltd, China. Epoxy resin was purchased from Guangzhou Shunyicheng Technology Co., Ltd, China. Water-based polishing paste $(\mathrm{W}=0.5)$ was purchased from Shanghai Naibo Testing Technology Co., Ltd, China. Deionized (DI) water with a specific resistance of $18.25 \mathrm{M} \Omega \cdot \mathrm{cm}$ was used in all our experiments.

\section{Simulated $\mathrm{Ag}-\mathrm{Cu}$ alloy flake sample preparation}

A simulated $\mathrm{Ag}-\mathrm{Cu}$ alloy sample was prepared by annealing silver-copper (94-6\%, wt.\%) at $1260{ }^{\circ} \mathrm{C}$ in a REXC100 Electric Heating Crucible Furnace for 5 min and then naturally cooled to room temperature. The alloy was then pressed to a thickness of $0.5 \mathrm{~mm}$ by a metal sheet pressing machine and cut into $80 \mathrm{~mm} \times 8 \mathrm{~mm} \times 0.5 \mathrm{~mm}$ rectangular alloy flakes. The alloy flake samples further underwent two-step thermal treatments in vacuum quartz tubes using an SX-G04133 muffle furnace, which is shown in Fig. $1\left(860^{\circ} \mathrm{C}\right.$ for $15 \mathrm{~min}$ and then $200^{\circ} \mathrm{C}$ for $2 \mathrm{~h})$.

\section{Characterization methods}

SEM images were taken by a QUANTA FE450 Field Emission-Scanning Electron Microscope $(20.00 \mathrm{kV}$, 5.97e-3 Pa). SEM-EDS analysis was carried out by a Hitachi TM3030 scanning electron microscope and BRUKER energy dispersive X-ray spectroscopy $(15.00 \mathrm{kV}$, low vacuum, 90 120 s). Metallographic images were taken by a Shangguang 13XF-PC Metallographic Microscope. The elemental compositions were measured on solutions using inductively coupled plasma-atomic emission spectrometry (ICP-AES) produced by Leeman Labs (RF power of $1.1 \mathrm{~kW}$, argon gas flow rate of $20 \mathrm{~L} / \mathrm{min}$, and nebuliser gas at $20 \mathrm{MPa}$ ). Three-point bending tests (Fig. 1) were carried out by a QuaLitesT QT-01 Universal Testing Machine $\left(P_{\text {sensor }}=50 \mathrm{~N}, \mathrm{l}=36 \mathrm{~mm}, \mathrm{~b}=8 \mathrm{~mm}\right.$, $\mathrm{h}=0.5 \mathrm{~mm}$ ). Microhardness tests (Fig. 1) were carried out by a Shangguang MVK-H21 Digital Microhardness Tester.

\section{Simulated Ag-Cu alloy flake samples accelerated aging test}

The 1st stage. (1) A solution of $1 \mathrm{~mol} / \mathrm{L} \mathrm{NO}_{3}$ was prepared. The flake sample was then immersed in $1000 \mathrm{~mL}$ of the above solution. Air was continuously blown into the solution, and the above reaction system was left for 30 days. (2) A solution of $0.25 \mathrm{~mol} / \mathrm{L} \mathrm{Fe}_{2}\left(\mathrm{SO}_{4}\right)_{3}$ was prepared, and the flake sample was then immersed in $30 \mathrm{~mL}$ of the above solution for 10 days. (3) A solution of $0.5 \mathrm{~mol} / \mathrm{L} \mathrm{NH}_{4} \mathrm{Fe}\left(\mathrm{SO}_{4}\right)_{2}$ was prepared, and the flake sample was then immersed in $30 \mathrm{~mL}$ of the above solution for 10 days. (4) The flake sample was immersed in $30 \mathrm{~mL}$ of the used solution of (2) for 10 days. (5) A solution of 


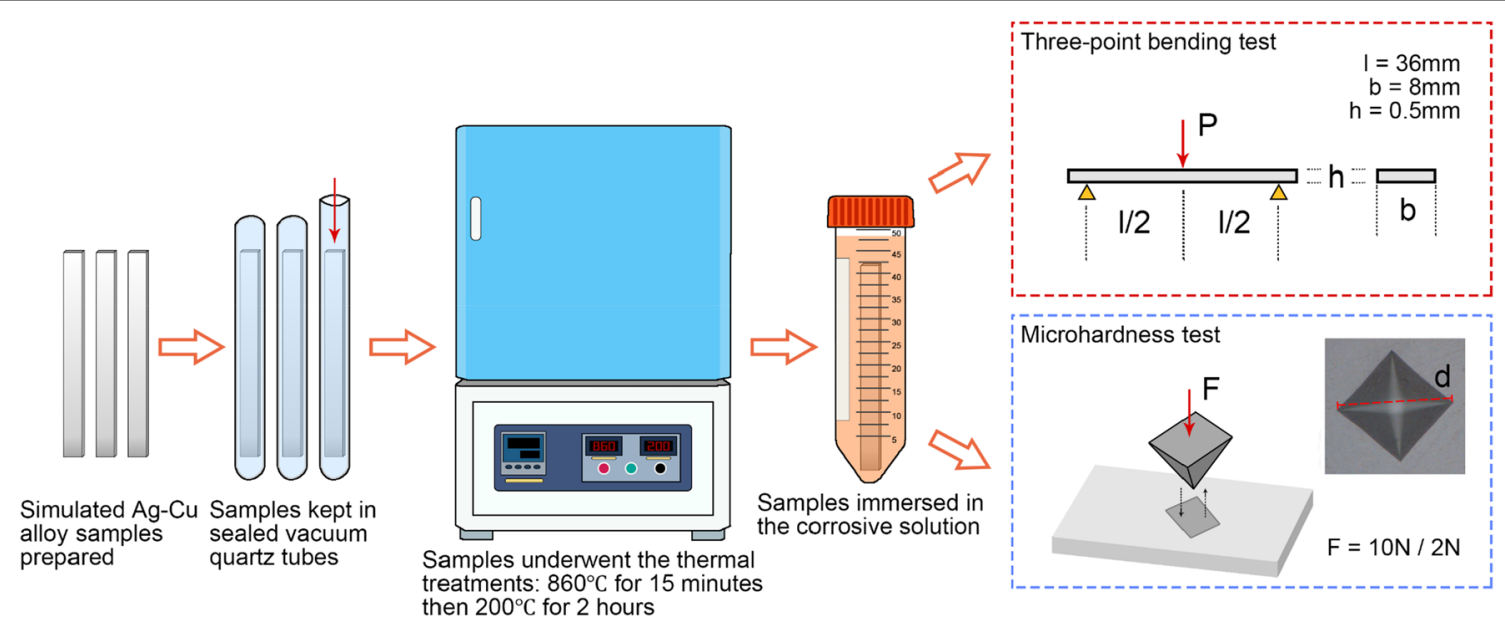

Fig. 1 Experimental method: preparation of the simulated $\mathrm{Ag}-\mathrm{Cu}$ alloy flake samples, accelerated aging of the simulated samples, and mechanical tests (three-point bending test and microhardness test) of the corroded samples

$0.25 \mathrm{~mol} / \mathrm{L} \mathrm{Fe}_{2}\left(\mathrm{SO}_{4}\right)_{3}+$ saturated $\mathrm{FeSO}_{4}$ was prepared, and the flake sample was then immersed in $30 \mathrm{~mL}$ of the above solution for 10 days. (6) A solution of $5 \mathrm{~mol} / \mathrm{L}$ $\mathrm{AgNO}_{3}$ was prepared, and the flake sample was then immersed in $30 \mathrm{~mL}$ of the above solution for 10 days. (7) A solution of $0.5 \mathrm{~mol} / \mathrm{L} \mathrm{Fe}\left(\mathrm{NO}_{3}\right)_{3}$ was prepared, and the flake sample was then immersed in $30 \mathrm{~mL}$ of the above solution for 3 days. (8) A solution of $0.5 \mathrm{~mol} / \mathrm{L}$ $\mathrm{Fe}\left(\mathrm{NO}_{3}\right)_{3}+0.5 \mathrm{~mol} / \mathrm{L} \mathrm{AgNO}_{3}$ was prepared, and the flake sample was then immersed in $30 \mathrm{~mL}$ of the above solution for 3 days.

The $2^{\text {nd }}$ stage. Solutions of $0.1 \mathrm{~mol} / \mathrm{L} \mathrm{Fe}\left(\mathrm{NO}_{3}\right)_{3}+0.1$ $\mathrm{mol} / \mathrm{L} \mathrm{AgNO}_{3}, 0.1 \mathrm{~mol} / \mathrm{L} \mathrm{Fe}\left(\mathrm{NO}_{3}\right)_{3}+0.4 \mathrm{~mol} / \mathrm{L} \mathrm{AgNO}_{3}$, $0.1 \mathrm{~mol} / \mathrm{L} \mathrm{Fe}\left(\mathrm{NO}_{3}\right)_{3}+1.0 \mathrm{~mol} / \mathrm{L} \quad \mathrm{AgNO}_{3}, 0.25 \mathrm{~mol} / \mathrm{L}$ $\mathrm{Fe}\left(\mathrm{NO}_{3}\right)_{3}+0.5 \mathrm{~mol} / \mathrm{L} \mathrm{AgNO}_{3}$ and $0.25 \mathrm{~mol} / \mathrm{L} \mathrm{Fe}\left(\mathrm{NO}_{3}\right)_{3}$ $+1.0 \mathrm{~mol} / \mathrm{L}_{\mathrm{AgNO}_{3}}$ were prepared. The flake samples were separately immersed in $30 \mathrm{~mL}$ of the above solutions for 3 days. (The as-prepared samples were cut into $10 \mathrm{~mm} \times 8 \mathrm{~mm} \times 0.5 \mathrm{~mm}$ flakes in the 1st stage and 2 nd stage.)

The 3rd stage. Solutions of $0.1 \mathrm{~mol} / \mathrm{L} \mathrm{Fe}\left(\mathrm{NO}_{3}\right)_{3}+1.0 \mathrm{~mol} / \mathrm{L}$ $\mathrm{AgNO}_{3}$ were prepared. The flake samples $(80 \mathrm{~mm} \times 8 \mathrm{~mm} \times 0.5 \mathrm{~mm})$ were separately immersed in $50 \mathrm{~mL}$ of the above solutions for 27 days.

Different aging schemes were performed independently and simultaneously, and all the accelerated aging tests were carried out in a laboratory environment at normal pressure and temperature (NPT).

\section{Thermal treatments of flake samples with intergranular corrosion}

The immersed flake samples in the 3rd stage further underwent thermal treatments in air by an SX-G04133 muffle furnace. Every three parallel flake samples were annealed at 200, 250,300,350, 400, 450, 500, 550, 600, $650,700,750,800,850,900$ and $950{ }^{\circ} \mathrm{C}$ respectively for $15 \mathrm{~min}$. The three-point bending tests and microhardness tests were then performed on the annealed flake samples.

\section{The embedding of samples}

The flake samples prepared for taking metallographic images, SEM-EDS tests and microhardness tests were embedded in epoxy resin and finally polished by using water-soluble polishing paste by a PG-1A Metallographic Sample Polishing Machine.

\section{Results and discussion}

Preparation of the simulated $\mathrm{Ag}-\mathrm{Cu}$ alloy flake samples

To study the effect of thermal treatments on brittle archaeological silver artifacts, we need to prepare simulated $\mathrm{Ag}-\mathrm{Cu}$ alloy flake samples with intergranular corrosion. In our former work [10], we studied the composition and microstructure of a brittle archaeological silver artifact unearthed from Guizhou Province, China, and found intracrystalline red-brown particles with high $\mathrm{Cu}$ and $\mathrm{O}$ contents in the dark field, which can be considered key evidence of whether the simulated samples we prepared conform to the similar microstructure of archaeological silver artifacts [37].

In this paper, $\mathrm{Ag} 94 \%-\mathrm{Cu} 6 \%$ alloy flake samples were prepared, and microstructures similar to those of archaeological silver artifacts were obtained by optimized thermal treatments $\left(860{ }^{\circ} \mathrm{C}\right.$ for $15 \mathrm{~min}$ and then $200{ }^{\circ} \mathrm{C}$ for $2 \mathrm{~h}$ in vacuum quartz tubes, Additional file 1: Fig. S2a). Annealing at $860{ }^{\circ} \mathrm{C}$ can not only enable us to obtain samples with the $\beta$ phase but can also prevent them from undergoing deformation due to excessive thermal treatments (Additional file 1: Fig. S2b), which may affect the 
results of subsequent mechanical tests. In addition, keeping the samples in vacuum quartz tubes can prevent oxidation during annealing (Additional file 1: Fig. S2c). Figure 2a is a sectional metallographic image of the $\mathrm{Ag}-$ $\mathrm{Cu}$ alloy flake sample we obtained by thermal treatments. Orange grain boundaries and intracrystalline particles are quite visible. EDS mapping analysis shows that the composition of the region in the red box is Ag 92.07\%$\mathrm{Cu} 7.93 \%$, whose $\mathrm{Cu}$ is slightly higher than the sample charge ratio. The elemental distribution (Fig. 2a, upper right) shows that $\mathrm{Ag}$ is mainly distributed in the $\alpha$ matrix, while $\mathrm{Cu}$ is mainly distributed in the grain boundary and the particles $(\beta)$. The EDS spot analysis also confirms the results above (Additional file 1: Fig. S3, spot 1: Ag 93.36\%-Cu 6.64\%, spot 2: Ag 94.95\%-Cu 5.05\%, spot 3: Ag 78.35\%-Cu 21.65\%, spot 4: Ag 58.19\%-Cu 41.81\%). These results demonstrated that the microstructures of the prepared $\mathrm{Ag}-\mathrm{Cu}$ alloy flake samples were consistent with
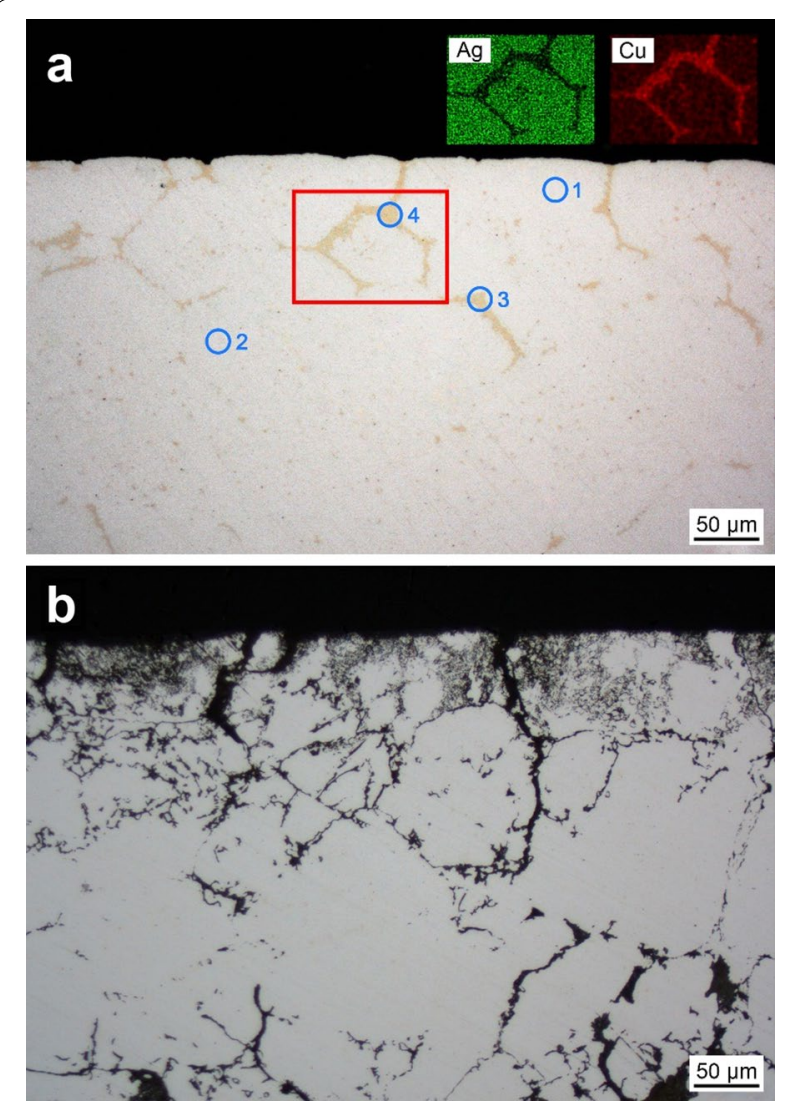

Fig. 2 Simulated Ag-Cu alloy samples before/after accelerated aging. a Microstructure of the original simulated $\mathrm{Ag}-\mathrm{Cu}$ alloy samples, the region of EDS mapping analysis (red box), the elemental distribution (upper right), and the position of EDS spot analysis (spots 1-4). b Microstructure of the corroded simulated Ag-Cu alloy samples (the phenomenon of intergranular corrosion is obvious) those of the archaeological silver artifacts with uncor$\operatorname{roded} \beta$ phase.

\section{Accelerated aging of the simulated $\mathrm{Ag}-\mathrm{Cu}$ alloy flake samples}

To obtain simulated $\mathrm{Ag}-\mathrm{Cu}$ alloy flake samples with intergranular corrosion, accelerated aging is necessary. Different schemes were adopted to accelerate the aging of the samples respectively, and the results are as follows (detailed schemed are described in 2.4).

The 1st stage. (1) Judging from the external metallographic image of the aged sample, the reaction system has good selectivity for intergranular corrosion, but from the sectional metallographic image, corrosion has not yet occurred inside the sample (Additional file 1: Fig. S4). (2) (3) $\mathrm{Fe}^{3+}$ can significantly accelerate corrosion, but due to the presence of $\mathrm{SO}_{4}{ }^{2-}$, the potential of silver is reduced [10], resulting in more loss of the $\alpha$ phase. In addition, $\mathrm{NH}_{4}{ }^{+}$has no effect on the corrosion phenomenon (Additional file 1: Fig. S5, S6). (4) (5) The reduction of the $\mathrm{Fe}^{3+} /$ $\mathrm{Fe}^{2+}$ ratio can make the intergranular corrosion more significant, but there is still much loss of the $\alpha$ phase (Additional file 1: Fig. S7, S8). (6) $\mathrm{Ag}^{+}$has good selectivity for intergranular corrosion. However, due to the precipitation of $\mathrm{Ag}$ produced during this process, which hinders the subsequent reaction, there is no corrosion inside the sample (Additional file 1: Fig. S9). (7) The oxidizing ability of $\mathrm{Fe}\left(\mathrm{NO}_{3}\right)_{3}$ is too strong, and the sample has been completely dissolved. (8) Due to the presence of $\mathrm{Ag}^{+}$, the potential of silver is increased, resulting in less loss of the $\alpha$ phase and better selectivity for intergranular corrosion (Additional file 1: Fig. S10).

On the basis of the above primary survey of oxidizing reagents, the $\mathrm{Fe}\left(\mathrm{NO}_{3}\right)_{3}-\mathrm{AgNO}_{3}$ system exhibited more desirable control over intergranular corrosion. Therefore, different ratios of $\mathrm{Ag}^{+} / \mathrm{Fe}^{3+}$ were adjusted to improve the results of the accelerated aging process.

The $2^{\text {nd }}$ stage. Solutions of different $\mathrm{Fe}\left(\mathrm{NO}_{3}\right)_{3}-\mathrm{AgNO}_{3}$ ratios were prepared in this stage. Judging from the acquired sectional metallographic images (Additional file 1: Fig. S11-S15), it can be summarized that by reducing the concentration of $\mathrm{Fe}^{3+}$ or increasing the ratio of $\mathrm{Ag}^{+} / \mathrm{Fe}^{3+}$, the loss of the $\alpha$ phase can be effectively controlled, and the aging process of intergranular corrosion can be well enhanced. Considering the duration of accelerated aging and the cost of this part, we finally chose a solution of $0.1 \mathrm{~mol} / \mathrm{L} \mathrm{Fe}\left(\mathrm{NO}_{3}\right)_{3}+1.0 \mathrm{~mol} / \mathrm{L} \mathrm{AgNO}_{3}$ as the accelerated aging reagent.

The 3rd stage. During the accelerated aging process, the changes in the microstructure of the samples can be clearly observed (Additional file 1: Fig. S16). After 27 days of accelerated aging, simulated $\mathrm{Ag}-\mathrm{Cu}$ alloy flake samples of intergranular corrosion were obtained $\left(\mathrm{S}_{\text {corr }}\right)$. The 
metallographic image in Fig. $2 \mathrm{~b}$ shows that the $\beta$ phase of $\mathrm{S}_{\text {corr }}$ has been completely corroded, and the phenomenon of intergranular corrosion is obvious, which is similar to the unearthed archaeological silver artifacts. EDS mapping analysis shows that the composition of $\mathrm{S}_{\text {corr }}$ is $\mathrm{Ag}$ $95.10 \%-\mathrm{Cu} 4.90 \%$, whose content of $\mathrm{Cu}$ has decreased by approximately $1 \%$ compared to the original flake samples $\left(\mathrm{S}_{\text {no corr }}\right)$. The ICP-AES results show that $\mathrm{c}\left(\mathrm{Cu}^{2+}\right)$ of the solutions after the accelerated aging process is $0.583 \mathrm{~g} / \mathrm{L}$ (equivalent to $0.029 \mathrm{~g}$, standard deviation $0.003 \mathrm{~g} / \mathrm{L}$ ), which is consistent with the mass loss of $\mathrm{Cu}$ in the EDS results calculated.

\section{Effect of thermal treatments on corroded flake samples}

In this section, we highlight the effect of thermal treatments on the simulated $\mathrm{Ag}-\mathrm{Cu}$ alloy flake samples with intergranular corrosion. Every three parallel flake samples were annealed at 200, 250,300, 350,400, 450, 500, $550,600,650,700,750,800,850,900$ and $950{ }^{\circ} \mathrm{C}$ respectively (labelled as $S_{200}, S_{250}$, $S_{300}$, etc.) for $15 \mathrm{~min}$. Except for $\mathrm{S}_{950}$ melting due to high temperature, the others were in good shape after annealing.

Three-point bending tests were carried out to characterize the mechanical strength of the flake samples we obtained (Additional file 1: Fig. S17-S33). The maximum load that the sensor can support is $50 \mathrm{~N}\left(\mathrm{P}_{\text {sensor }}\right)$, and the load span (l) is $36 \mathrm{~mm}$. The width (b) of the samples is $8 \mathrm{~mm}$, and the thickness (h) of the sample is $0.5 \mathrm{~mm}$. A constant-speed downpressing mode was chosen during the tests (speed $=10 \mathrm{~mm} / \mathrm{min}$ ). When the instantaneous load reached $1 \%$ of $\mathrm{P}_{\text {sensor }}$, the data began to be recorded, and when the instantaneous load (P) attenuated $30 \%$ of the maximum instantaneous load $\left(\mathrm{P}_{\max }\right)$ or the indenter displacement $(\mathrm{x})$ reached $12 \mathrm{~mm}$, the tests stopped. Finally, the load-displacement curves (P-x) of the samples were obtained (Fig. 3a-c).

Judging from the P-x curves, the mechanical strength of $S_{\text {corr }}$ is significantly lower than that of $S_{\text {no corr }}$ within expectations, and different thermal treatments restored the mechanical strength of $\mathrm{S}_{\text {corr }}$ to varying degrees. When the temperature of thermal treatments ( $\mathrm{T}$ ) was lower than $800{ }^{\circ} \mathrm{C}$, some samples in each group had different degrees of fracture (Fig. 3a, b, P attenuated 30\% of $\mathrm{P}_{\max }$ ). In contrast, when the temperature was higher than or equal to $800^{\circ} \mathrm{C}$, none of the samples fractured (Fig. 3c, $\mathrm{x}$ reached $12 \mathrm{~mm}$ ).

Furthermore, when $200{ }^{\circ} \mathrm{C}<\mathrm{T} \leq 500{ }^{\circ} \mathrm{C}$, the mechanical strength of the samples increased as $\mathrm{T}$ increased (Fig. 3a), and when $500{ }^{\circ} \mathrm{C} \leq \mathrm{T}<800{ }^{\circ} \mathrm{C}$, the mechanical strength decreased as $\mathrm{T}$ increased (Fig. 3b). It is worth noting that the mechanical strength of $\mathrm{S}_{800}$ is significantly higher than that of $\mathrm{S}_{750}$. However, when $800{ }^{\circ} \mathrm{C} \leq \mathrm{T} \leq 900{ }^{\circ} \mathrm{C}$, the mechanical strength decreased as $\mathrm{T}$ increased (Fig. 3c).
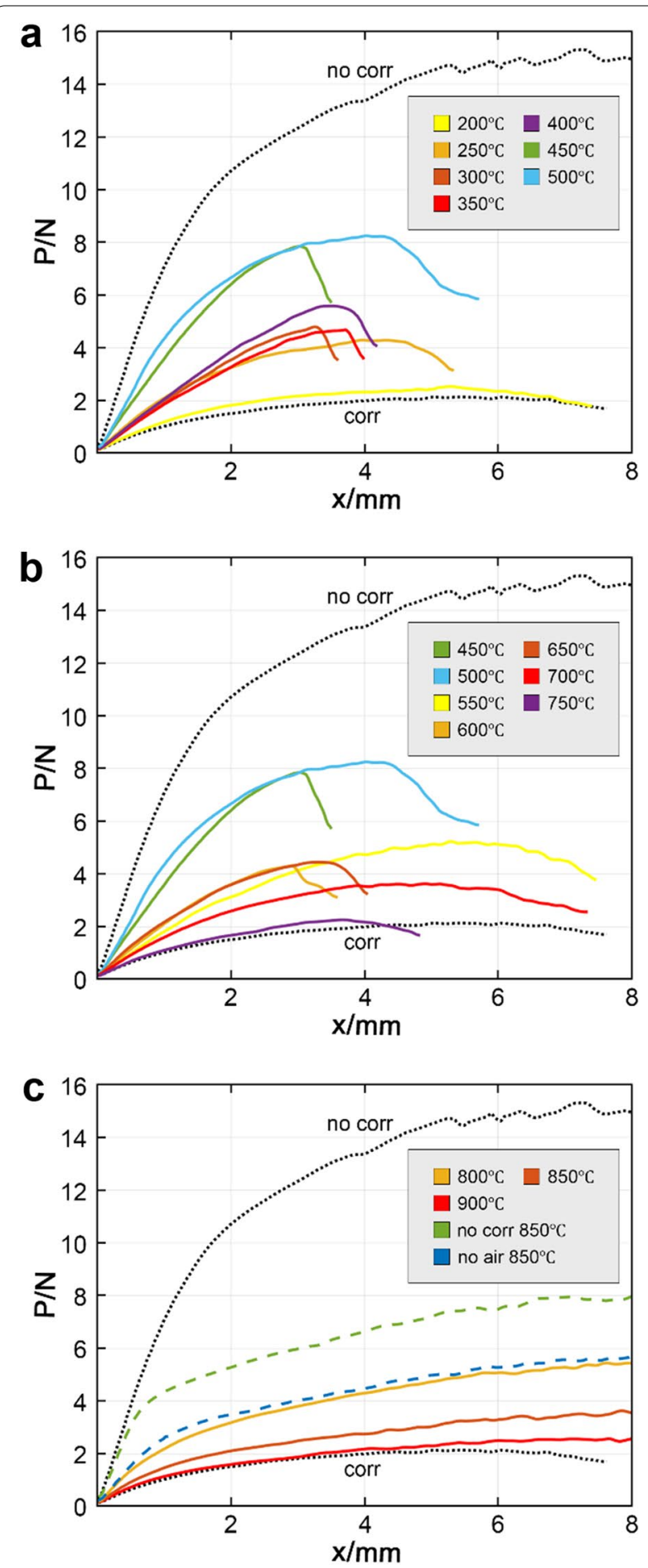

Fig. 3 Load-displacement curves ( $P-x)$ of the samples obtained by three-point bending tests (black dotted lines: no corr- $S_{\text {no corr }}$ the original simulated $\mathrm{Ag}-\mathrm{Cu}$ alloy samples; corr-S $\mathrm{S}_{\text {corr }}$ the corroded simulated Ag-Cu alloy samples). a $\mathrm{S}_{200}-\mathrm{S}_{500} \cdot \mathbf{b} \mathrm{S}_{450}-\mathrm{S}_{750} \cdot \mathbf{c} \mathrm{S}_{800}-\mathrm{S}_{900}$, $\mathrm{S}_{\text {no air } 850}$ (corroded samples annealed at $850^{\circ} \mathrm{C}$ for $15 \mathrm{~min}$ in vacuum quartz tubes), and $\mathrm{S}_{\text {no corr } 850}$ (uncorroded samples annealed at $850^{\circ} \mathrm{C}$ for $15 \mathrm{~min}$ in air) 
To observe the effect of thermal treatment temperature on the mechanical strength of the corroded flake samples more intuitively, the maximum bending strength $\left(\sigma_{\mathrm{bb}}\right)$ and elastic modulus $\left(\mathrm{E}_{\mathrm{b}}\right)$ of the samples were calculated based on the results of the three-point bending tests (Additional file 1: Tables S1-S17) with the help of MATLAB (Additional file 1: Table S18). The equations are as follows $[25,26]$.

$$
\begin{aligned}
\sigma_{b b} & =\frac{3 P_{\max } \times l}{2 b h^{2}} \\
E_{b} & =\frac{l^{3}}{4 b h^{3}} \times\left(\frac{\Delta P}{\Delta f}\right)
\end{aligned}
$$

where $\mathrm{f}$ is the deflection and $\frac{\Delta P}{\Delta f}$ is the slope of the $\mathrm{P}-\mathrm{f}$ curve. When the deformation of the samples is not too large ( $x \leq 0.3 \mathrm{~mm}$ in this study), we consider $\mathrm{f}=\mathrm{x}$ to simplify the model. Other physical quantities have been explained above. The calculation results of $\sigma_{\mathrm{bb}}$ (light red) and $\mathrm{E}_{\mathrm{b}}$ (light blue) are shown in the histogram in Fig. 4, and the conclusions obtained from them are almost the same as the P-x curve.

In addition to the three-point bending tests, microhardness tests were also carried out to characterize the mechanical strength of the annealed samples. A constant-load downpressing mode was chosen during the tests (indenter load $\mathrm{F}=10 \mathrm{~N}$, contact time $\mathrm{t}=10 \mathrm{~s}$ ).
After the test, a diamond-shaped indentation was left on the surface of the sample (Additional file 1: Fig. S34). The Vickers hardness (HV) of the sample was calculated based on measuring the length of the two diagonal lines $\left(\mathrm{d}_{1}\right.$ and $\left.\mathrm{d}_{2}\right)$ of the diamond-shaped indentation (Additional file 1: Tables S1-S17). The equation for calculating $\mathrm{HV}$ is as follows [32-34].

$$
H V=0.102 \frac{F}{\frac{d_{1} d_{2}}{2 \sin \frac{\theta}{2}}}=0.1891 \frac{F}{d_{1} d_{2}}
$$

The calculation results of HV (light green) are shown in the histogram in Fig. 4, and the change trend is nearly the same $\left(\mathrm{S}_{200}<\mathrm{S}_{250}<\ldots<\mathrm{S}_{500}, \mathrm{~S}_{500}>\mathrm{S}_{550}>\ldots>\mathrm{S}_{750}\right.$, and $\left.\mathrm{S}_{750}<\mathrm{S}_{800}>\mathrm{S}_{850}>\mathrm{S}_{900}\right)$.

\section{Mechanism of the mechanical strength changes}

The metallographic images show that the effect of thermal treatments on the microstructure of the corroded flake samples are mainly in the following three aspects (Additional file 1: Fig. S35).

Effect (1). The $\alpha$ grains grew slowly (Additional file 1: Fig. S35a-c, the morphology of the intergranular cracks became smooth), and correspondingly, the mechanical strength of the samples increased. This process occurs when the temperature reaches $200{ }^{\circ} \mathrm{C}$.

Effect (2). Recrystallization occurred, the intergranular cracks were healed, and the mechanical strength of the

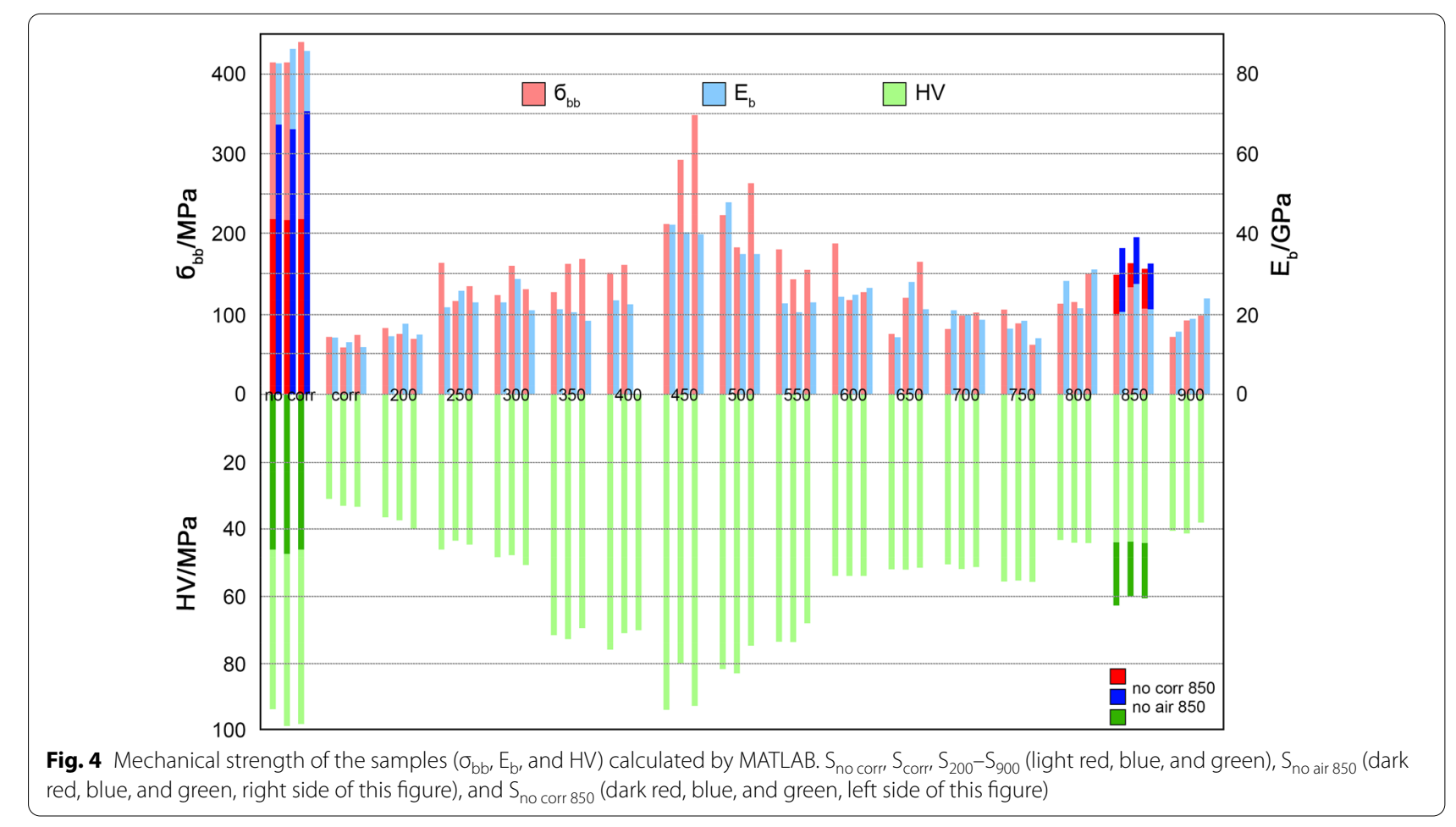


a
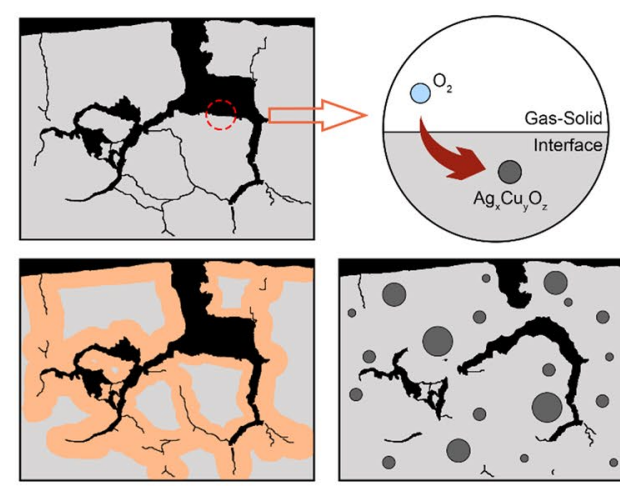

Low Efficient Recrystallization

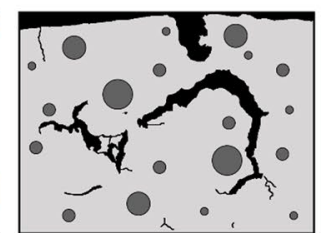

Highly Efficient Recrystallization
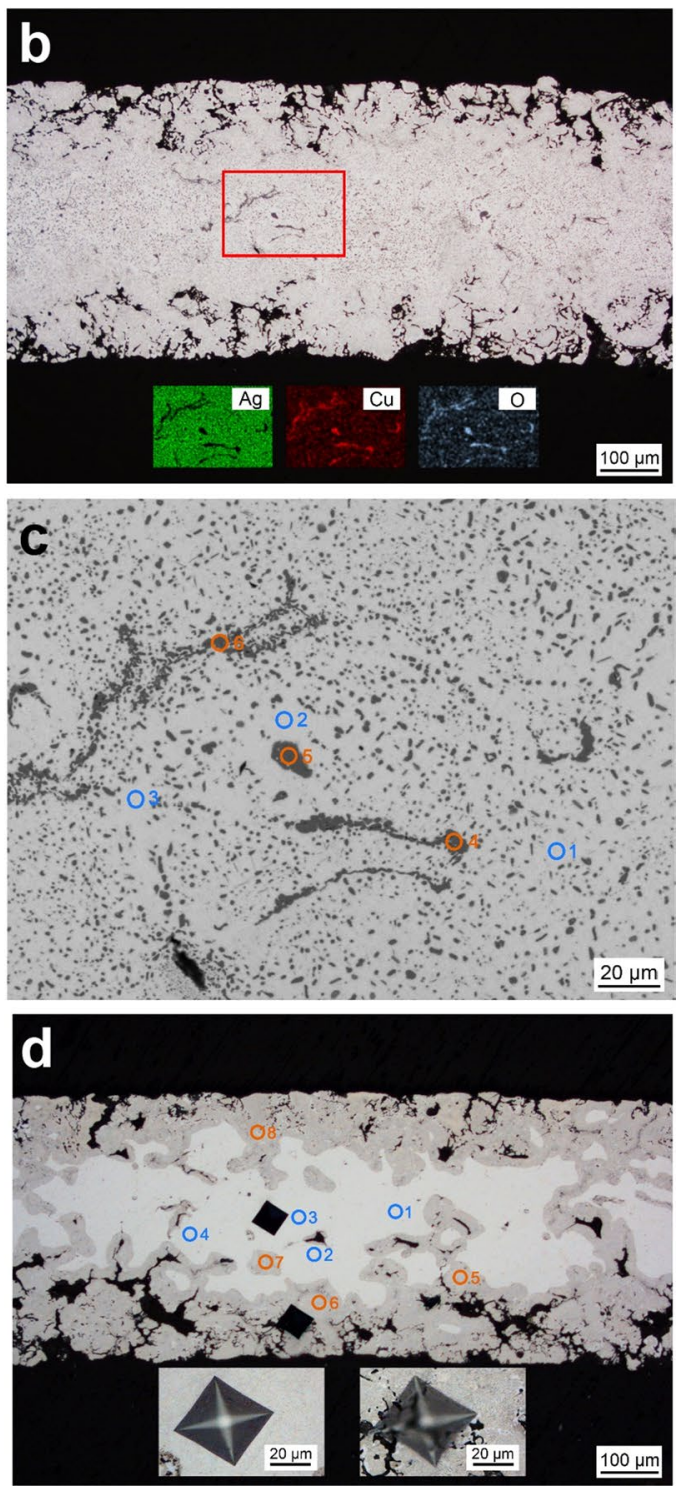

4 Fig. 5 Oxidation reaction during recrystallization. a Mechanism of the oxidation reaction. Highly efficient recrystallization (bottom right): the intergranular cracks in the core of the samples are completely healed, and the products of the oxidation are distributed in the grain boundaries or inside the a grains in the form of gray-black particles. Low efficient recrystallization (bottom left): the intergranular cracks are slightly healed, and the oxidation products are only distributed in a limited range (dark area, orange in the schematics) due to the lower efficiency of recrystallization and diffusion. $\mathbf{b}$ Microstructure of $\mathrm{S}_{850}$, the region of EDS mapping analysis (red box), and the elemental distribution (under b). c Microstructure of $\mathrm{S}_{850}$ (red box in b, partially enlarged view) and the position of EDS spot analysis (spots 1-6). $\mathbf{d}$ Microstructure of $S_{550}$, the position of EDS spot analysis (spots 1-8), and the microhardness indentations of the light/dark area (partial enlarged view)

samples increased. When the temperature rose to $800{ }^{\circ} \mathrm{C}$ and above, the intergranular cracks in the core of the samples were completely healed (Additional file 1: Fig. $\mathrm{S} 35 \mathrm{~m}-\mathrm{o}$ ). This may explain why the samples of the threepoint bending tests were fractured when the thermal treatment temperature was less than or equal to $750{ }^{\circ} \mathrm{C}$ and the significant increase in the mechanical strength of $\mathrm{S}_{800}$ compared to that of $\mathrm{S}_{750}$.

Effect (3). The matrix of the samples underwent oxidation during recrystallization, which mainly manifested in two ways in the microstructure due to the difference in the temperature of the thermal treatment and the efficiency of recrystallization. For the sake of discussion, the analysis will be divided into two intervals, $\mathrm{T} \geq 800{ }^{\circ} \mathrm{C}$ and $\mathrm{T}<800{ }^{\circ} \mathrm{C}$, in the following. When the temperature was higher than or equal to $800{ }^{\circ} \mathrm{C}$, the metal atoms $\mathrm{Ag}$ and $\mathrm{Cu}$ at the matrix-air interface (solid-gas interface) underwent a relatively rapid oxidation reaction with $\mathrm{O}_{2}$, and the oxidation products moved and diffused to the inner part of the matrix with the highly efficient recrystallization process. At this time, a large number of grayblack particles can be observed in the grain boundaries or inside the $\alpha$ grains (Fig. 5a, bottom right).

Taking $\mathrm{S}_{850}$ as an example (Fig. 5b), EDS mapping analysis shows that the composition of the region in the red box is $\mathrm{Ag} 88.50 \%-\mathrm{Cu} 7.61 \%-\mathrm{O} 3.89 \%$. It can be found in the elemental distribution that $\mathrm{Ag}$ is mainly distributed in the $\alpha$ matrix, while $\mathrm{Cu}$ and $\mathrm{O}$ are distributed in the gray-black particles. The spot analysis (Fig. 5c) shows that the $\mathrm{Cu}$ content in the particles is much higher than that in the corroded $\mathrm{Ag}-\mathrm{Cu}$ alloy flake samples (Fig. 2b, 4.90\%), which indicates that more $\mathrm{Cu}$ in the $\mathrm{Ag}-\mathrm{Cu}$ alloy solid solution was precipitated in the form of oxides $\left(\mathrm{Ag}_{\mathrm{x}} \mathrm{Cu}_{\mathrm{y}} \mathrm{O}_{\mathrm{z}}\right)$ during thermal treatments. Thus, due to the decrease in the $\mathrm{Cu}$ content in the $\mathrm{Ag}-\mathrm{Cu}$ alloy solid solution, the mechanical strength of the samples 
Table 1 Three kinds of effects caused by thermal treatments and together affecting the microstructure and the mechanical strength $\left(\sigma_{b b}, E_{b}\right.$, and $\left.H V\right)$ of the samples (effect (1): grain growth, effect (2): recrystallization, effect (3): oxidation reactions)

\begin{tabular}{|c|c|c|c|c|c|}
\hline Temperature $\left({ }^{\circ} \mathrm{C}\right)$ & Recrystallization & Existential effect & Dominant effect & $\begin{array}{l}\text { Trend of mechanical } \\
\text { strength }\left(\sigma_{b b} / E_{b} / H V\right)\end{array}$ & $\begin{array}{l}\text { Maximum } \\
\text { value } \\
\text { produced }\end{array}$ \\
\hline $200-350$ & - & (1) & (1) & $\uparrow$ & - \\
\hline $350-500$ & Low efficient & (1)(2)(3) & (1)(2) & $\uparrow$ & $\mathrm{S}_{500}$ \\
\hline $500-750$ & Low efficient & (1)(2)(3) & (3) & $\downarrow$ & \\
\hline $750-800$ & Highly efficient & (1)(2)(3) & (2) & $\uparrow$ & $\mathrm{S}_{800}$ \\
\hline $800-900$ & Highly efficient & (1)(2)(3) & (3) & $\downarrow$ & \\
\hline
\end{tabular}

The combination of the three effects causes overall changes in the mechanical strength of the samples and produces maximum values of $S_{500}$ and $S_{800}$

decreased (Additional file 1: Fig. S36, spot 1: Ag 98.54\%$\mathrm{Cu} 1.07 \%-\mathrm{O} 0.39 \%$, spot 2: Ag 96.25\%-Cu 2.22\%-O 1.53\%, spot 3: Ag 97.77\%-Cu 1.10\%-O 1.11\%, spot 4: Ag 49.04\%$\mathrm{Cu} 38.34 \%-\mathrm{O} 12.62 \%$, spot 5: Ag 41.89\%-Cu 43.02\%-O 15.09\%, spot 6: Ag 60.56\%-Cu 28.14\%-O 11.29\%). The differences in mechanical strength between $\mathrm{S}_{850}$ and $\mathrm{S}_{\text {no air }}$ 850 (corroded samples annealed at $850{ }^{\circ} \mathrm{C}$ for $15 \mathrm{~min}$ in vacuum quartz tubes) and between $S_{\text {no corr }}$ and $S_{\text {no corr } 850}$ (uncorroded samples annealed at $850{ }^{\circ} \mathrm{C}$ for $15 \mathrm{~min}$ in air) support the viewpoint above (Figs. 3c, 4).

Furthermore, when the temperature was lower than $800{ }^{\circ} \mathrm{C}$, due to the lower efficiency of the oxidation reaction and recrystallization, the oxidation products could only be distributed in a limited range (Fig. 5a, bottom left, the dark area observed in the metallographic images, which can be regarded as evidence of recrystallization) close to the gas-solid interface (sample surface and intergranular cracks).

Taking $\mathrm{S}_{550}$ as an example (Fig. $5 \mathrm{~d}$ ), the spot analysis shows that the $\mathrm{O}$ content in the dark area is higher than that in the light area, which indicates that more $\mathrm{Cu}$ was oxidized so that there was less $\mathrm{Cu}$ in the $\mathrm{Ag}-\mathrm{Cu}$ alloy solid solution in the dark area (Additional file 1: Fig. S37, spot 1: O $0.66 \%$, spot 2: O $0.07 \%$, spot 3: O $0.61 \%$, spot 4: O $0.76 \%$, spot 5: O $1.81 \%$, spot 6: O 2.37\%, spot 7: O $2.71 \%$, spot 8: $\mathrm{O} 1.72 \%)$. The results of microhardness tests $(\mathrm{F}=2 \mathrm{~N}, \mathrm{t}=10 \mathrm{~s})$ support our viewpoint (light area: $\mathrm{d}_{1}=67.40 \mu \mathrm{m}, \mathrm{d}_{2}=66.92 \mu \mathrm{m}, \mathrm{HV}=82.13 \mathrm{MPa}$; dark area: $\mathrm{d}_{1}=69.60 \mu \mathrm{m}, \mathrm{d}_{2}=74.28 \mu \mathrm{m}, \mathrm{HV}=71.55 \mathrm{MPa}$ ).

In summary, there are three kinds of effects caused by thermal treatments on the microstructure of the samples. As the temperature rises, effect (1) and effect (2) can increase the mechanical strength of the samples, while effect (3) decreases it. The reason for the change trend of $\sigma_{\mathrm{bb}}, \mathrm{E}_{\mathrm{b}}$, and HV is presented in Table 1.

\section{Thermal treatments in the absence of $\mathrm{O}_{2}$}

Considering that thermal treatments in air will cause the oxidation reaction, which will reduce the mechanical strength and lead to a significant change in the microstructure of the samples, we tried to anneal the corroded $\mathrm{Ag}-\mathrm{Cu}$ alloy flake samples under anaerobic conditions. As mentioned above, the mechanical strength of the samples kept in vacuum quartz tubes and annealed at $850{ }^{\circ} \mathrm{C}$ for $15 \mathrm{~min}\left(\mathrm{~S}_{\mathrm{no} \text { air } 850}\right)$ is better than those samples directly annealed in air $\left(\mathrm{S}_{850}\right)$. At the same time, the metallographic images show that there are no gray-black particles in the grain boundaries or inside the $\alpha$ grains (Fig. 6a), which is suitable for the conservation of archaeological silver artifacts. The only shortcoming is that the secondary $\beta$ phase was found in the microstructure of the samples annealed in this way (Fig. 6b, EDS mapping analysis: $\mathrm{Ag} 95.18 \% \%-\mathrm{Cu} 4.82 \%-\mathrm{O} 0.00 \%$. Additional file 1: Fig. S38, spot 1: Ag 97.62\%-Cu 2.38\%, spot 2: Ag 96.52\%-Cu 3.48\%, spot 3: Ag 92.23\%-Cu 7.77\%, spot 4: Ag 91.61\%-Cu 8.39\%, spot 5: Ag 93.17\%-Cu 6.83\%, spot 6: $\mathrm{Ag} 89.24 \%-\mathrm{Cu} 10.76 \%$ ), which may lead to an increase in the sensitivity of intergranular corrosion. However, due to the subsequent corrosion inhibition, seal protection and relatively stable storage environment provided to the restored archaeological silver artifacts, the secondary $\beta$ phase might have no actual impact on the conservation of the archaeological silver artifacts. Therefore, thermal treatments in an oxygen-free environment (vacuum quartz tubes, tube furnace, reducing atmosphere, etc.) should be a good choice.

\section{Experiment on the optimal conditions of thermal treatments}

To ascertain the most suitable temperature and time of thermal treatments for the brittle archaeological silver artifacts, a series of comprehensive thermal treatments were carried out. The accelerated aging $\mathrm{Ag}-\mathrm{Cu}$ alloy flake samples we prepared were cut into $20 \mathrm{~mm} \times 8 \mathrm{~mm} \times 0.5 \mathrm{~mm}$ pieces and annealed at different temperatures for different durations (to simplify the experiments, the samples were directly annealed in air). We use simple bending experiments (Additional file 1: 

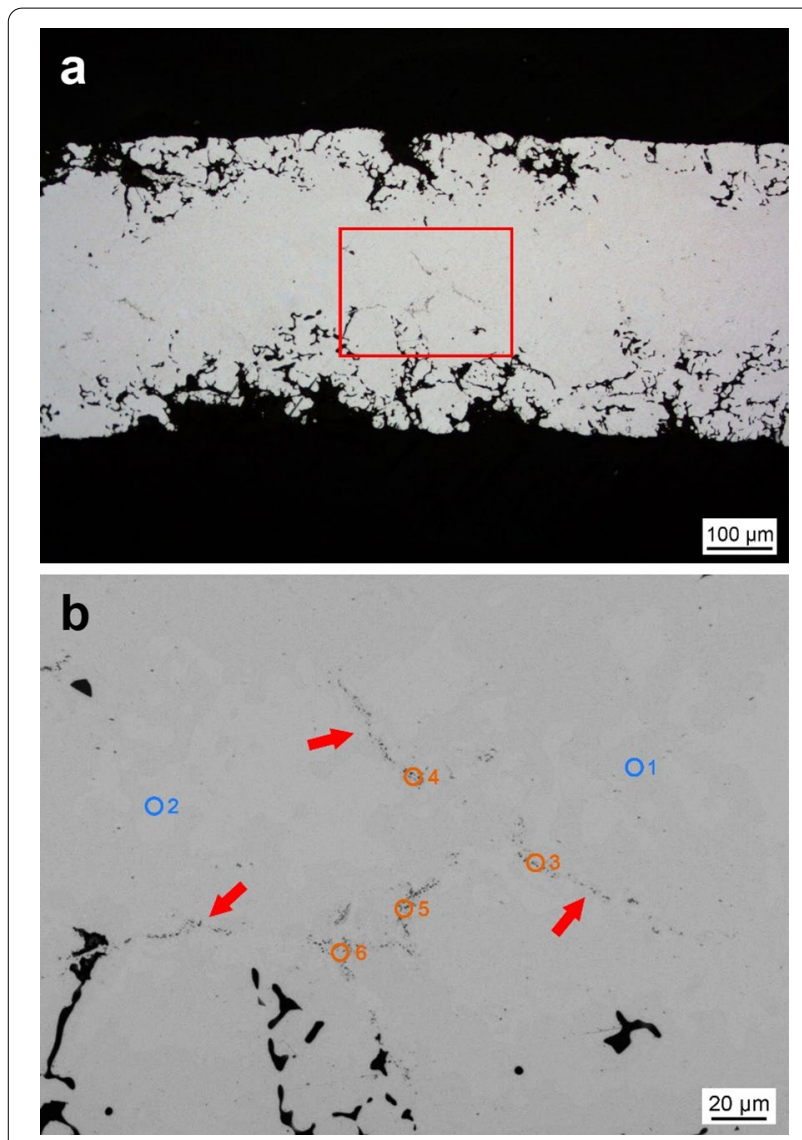

Fig. 6 Metallographs of samples after thermal treatments in the absence of $\mathrm{O}_{2}$. $\mathbf{a}$ Microstructure of $\mathrm{S}_{\text {no air } 850}$ and the region of EDS mapping analysis (red box). $\mathbf{b}$ Microstructure of $\mathrm{S}_{\text {no air } 850}$ (red box in $\mathbf{a}$, partially enlarged view), the position of EDS spot analysis (spots 1-6), and the secondary $\beta$ phase (red arrow) obtained through the thermal treatments in the oxygen-free environment

Fig. S39) to verify whether the annealed samples meet the requirements for shaping during restoration (Fig. 7a). Among them, "D" means that the annealed samples can withstand one bend without breaking, "O" means two, and " $O$ " means the samples break without being able to withstand one bend. Figure $7 \mathrm{a}$ shows that changes in temperature have a huge impact on the efficiency of recrystallization. A decrease in temperature by $100{ }^{\circ} \mathrm{C}$ may increase the time required to restore the mechanical performance of the brittle archaeological silver artifacts.

On this basis, the temperature-time map (T- $t$ ) of thermal treatments for the brittle archaeological silver artifacts is summarized in Fig. 7b. When the temperature is lower than $T_{0}\left(T_{0}\right.$ is approximately $\left.350{ }^{\circ} \mathrm{C}\right)$, no recrystallization occurs. In this case, no matter how long the thermal treatment is, the samples cannot recover good bending resistance (Null Zone). In addition, when the temperature is between $\mathrm{T}_{0}$ and $\mathrm{T}_{1}$ $\left(\mathrm{T}_{1}\right.$ is approximately $500{ }^{\circ} \mathrm{C}$ ), recrystallization occurs.

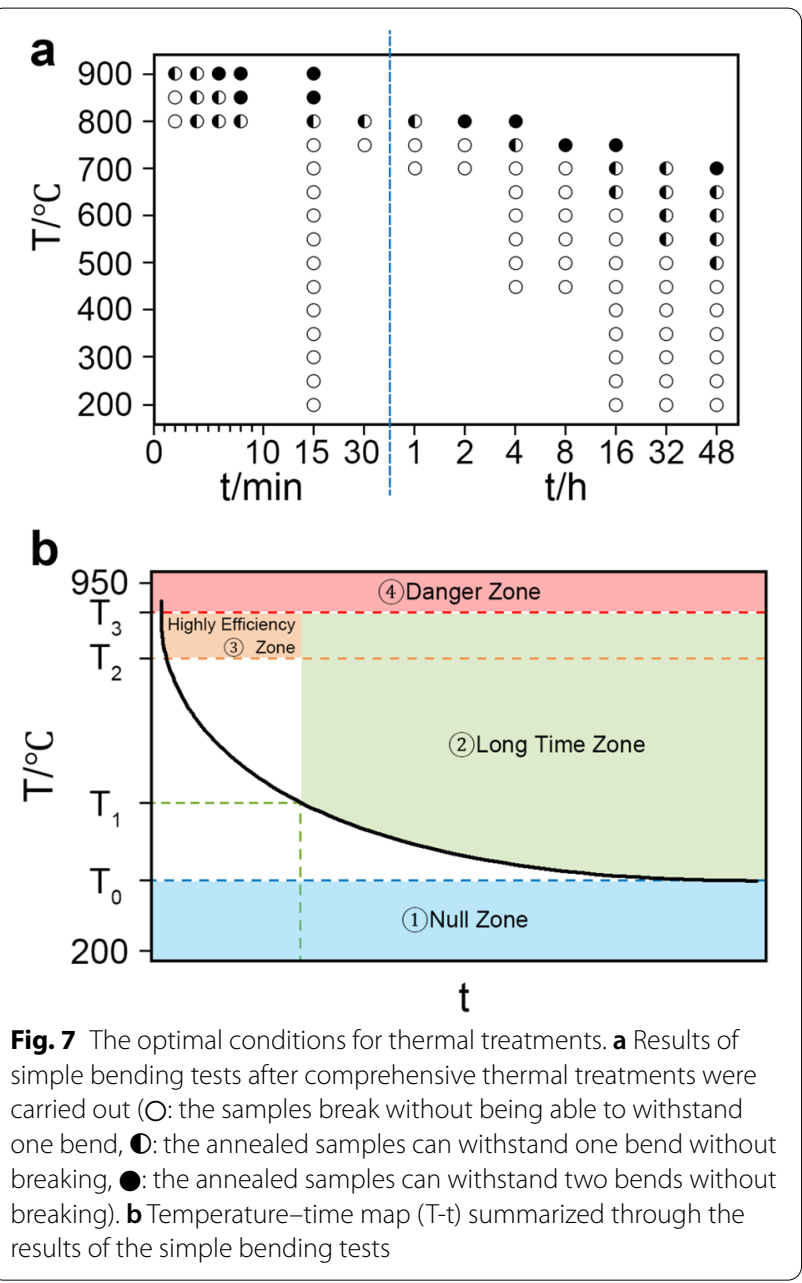

However, restoring the bending resistance takes too long (more than $48 \mathrm{~h}$, Long Time Zone). In addition, when the temperature is between $\mathrm{T}_{2}$ and $\mathrm{T}_{3}\left(\mathrm{~T}_{2}\right.$ is approximately $800^{\circ} \mathrm{C}, \mathrm{T}_{3}$ is between $900^{\circ} \mathrm{C}$ and $950{ }^{\circ} \mathrm{C}$ ), highly efficient recrystallization occurs. At this time, several hours or even minutes of thermal treatment can restore the performance of the samples (Highly Efficiency Zone). Finally, when the temperature is higher than $T_{3}$, the samples may deform or even melt due to excessively high temperature (Danger Zone). In summary, the most suitable temperature of thermal treatments is between $T_{1}$ and $T_{3}$, and the annealing time needed to restore the bending resistance of the samples is less than $48 \mathrm{~h}$. Caution must be taken that the conclusions drawn here are a general guidance established upon the corroded $\mathrm{Ag} 94 \%-\mathrm{Cu} 6 \%$ alloy. Changes in the specific critical temperatures should be adjusted with reference to specific compositions of the silver artifacts. 


\section{Conclusion}

In this study, we obtained $\mathrm{Ag}-\mathrm{Cu}$ alloy flake samples with intergranular corrosion similar to that of brittle archaeological silver artifacts through two-step annealing and accelerated aging in $\mathrm{Fe}\left(\mathrm{NO}_{3}\right)_{3}+\mathrm{AgNO}_{3}$ solution. Subsequently, SEM-EDS, metallographic observation, three-point bending tests, and microhardness tests were carried out to study the changes in the microstructures and mechanical strength $\left(\sigma_{b b}, E_{b}\right.$, and HV) of the samples after thermal treatments at different temperatures and the mechanism of the above changes. Grain growth, recrystallization and oxidation reactions are considered to be the main factors affecting the mechanical strength of the samples during the thermal treatments. Among them, the first two increase the mechanical strength, and the latter decrease the mechanical strength. The combined effect of the three causes the overall changes in the mechanical strength of the samples (and produces the maximum values $S_{500} / S_{800}$ ). In addition, the recovery of the bending resistance depends on the recrystallization efficiency (temperature) and the time of thermal treatments. The T-t map was summarized, and the most suitable temperature range for the thermal treatments was confirmed through a series of comprehensive thermal treatments. Finally, considering the irreversible effects of the oxidation reaction on the microstructures and mechanical strength of the samples, thermal treatments in the absence of $\mathrm{O}_{2}$ were recommended.

Prior to this study, due to the lack of methods to prepare simulated $\mathrm{Ag}-\mathrm{Cu}$ alloy flake samples with intergranular corrosion, no one has studied the effect of thermal treatments on brittle archaeological silver artifacts in a systematic and quantitative way. Our work provides an important reference for the restoration and conservation of brittle archaeological silver artifacts. In the future, we will also combine micro-area electrochemical analysis methods (e.g., SECM, SECCM, etc.) to screen corrosion inhibitors and sealing materials for silver-copper alloy samples with $\beta$ phase to cope with the corrosion of secondary $\beta$ phase that may precipitate in the matrix of brittle silver artifacts after thermal treatment in the absence of $\mathrm{O}_{2}$, so that the artifacts can be preserved in a longterm and stable manner.

\section{Supplementary Information}

The online version contains supplementary material available at https://doi. org/10.1186/s40494-022-00657-x.

Additional file 1: Figure S1. An example of restoration of brittle silver artifact by conventional thermal treatment (using high temperature torch). Figure S2. Preparation of the simulated Ag-Cu alloy flake samples. Figure S3. Position of spot analysis and EDS spectrum $\left(S_{\text {no corr }}\right)$. Figure S4-S15. Accelerated aging by different solutions. Figure S16. Accelerated aging by $0.1 \mathrm{M} \mathrm{Fe}\left(\mathrm{NO}_{3}\right)_{3}+1.0 \mathrm{M} \mathrm{AgNO}_{3}$ for 27 days. Figure S17-S33.
Load-displacement curves ( $P-x)$ of different samples obtained by threepoint bending tests (black dotted lines: no corr-S $S_{\text {no corr }}$ the original simulated Ag-Cu alloy samples; corr-S $\mathrm{S}_{\text {corr }}$ the corroded simulated $\mathrm{Ag}-\mathrm{Cu}$ alloy samples). Figure S34. The diamond-shaped indentation left on the surface of the sample after microhardness tests. Figure S35. The microstructure of the samples after thermal treatments. Figure $\mathbf{S 3 6}$. Position of spot analysis and EDS spectrum $\left(\mathrm{S}_{850}\right)$. Figure $\mathbf{S 3 7}$. Position of spot analysis and EDS spectrum $\left(\mathrm{S}_{550}\right)$. Figure $\mathbf{S 3 8}$. Position of spot analysis and EDS spectrum $\left(S_{\text {no air } 850}\right)$. Figure S39. Schematic diagram of simple-bending experiment. Table $\mathbf{S 1 - S 1 7 . ~ C a l c u l a t i o n ~ r e s u l t s ~ o f ~} \sigma_{b b}, E_{b}$, and $H V$ of different samples. Table S18. MATLAB code of P-f curve extrapolation.

\section{Acknowledgements}

We thank Dr. Ruiqi Wang from Peking University (Beijing National Laboratory for Molecular Sciences and State Key Laboratory of Rare Earth Materials Chemistry and Applications, College of Chemistry and Molecular Engineering) for the outstanding technical support on the preparation and characterization of the simulated $\mathrm{Ag}$-Cu alloy flake samples.

\section{Authors' contributions}

SL developed the concept, performed the experiments, and analyzed the experimental data. ZL contributed to accelerated aging tests and ICP-AES tests. SL, RL and ZX performed the three-point bending test and analyzed the data. SL, YZ and CL performed the microhardness test and analyzed the data. $\mathrm{SL}, \mathrm{ZL}$ and $\mathrm{YZ}$ wrote the manuscript. $\mathrm{GH}$ and $\mathrm{DH}$ designed and directed the project. All authors discussed the results and commented on the manuscript. All authors read and approved the final manuscript.

\section{Funding}

This research was financially supported by the National Key R\&D Program of China (No. 2019YFC1520201).

\section{Availability of data and materials}

The dataset supporting the conclusions of this article is included within the article (and its Additional Information file).

\section{Declarations}

\section{Competing interests}

The authors declare that they have no competing interests.

\section{Author details}

${ }^{1}$ The International Center for Chinese Heritage and Archaeology, School of Archaeology and Museology, Peking University, Beijing 100871, China. ${ }^{2}$ Institute for Advanced Study, Tsinghua University, Beijing 100084, China. ${ }^{3}$ School of Civil Engineering, Southwest Jiaotong University, Chengdu 610031, China.

Received: 1 November 2021 Accepted: 27 January 2022

Published online: 10 February 2022

\section{References}

1. Wanhill RJH. Archaeological silver embrittlement: a metallurgical inquiry. Amsterdam: National Aerospace Laboratory NLR; 2002.

2. Thompson FC, Chatterjee AK. The age-embrittlement of silver coins. Stud Conserv. 1954;1:115-26.

3. Ravich IG. Annealing of brittle archaeological silver: microstructural and technological study. Washington, DC: ICOM Committee for Conservation tenth triennial meeting; 1993.

4. Werner AE. Two problems in the conservation of antiquities: corroded lead and brittle silver. Boston: Boston Museum of Fine Arts; 1965.

5. Organ RM. The current status of the treatment of corroded metals, in Corrosion and Metal Artifacts. Washington, DC: National Bureau of Standards/US Department of Commerce; 1977.

6. Kallfass M, Paul J, Jehn H. Investigations on the embrittlement of an antique Roman silver bowl. Prakt Metallogr. 1985;22:317-23. 
7. Vaníčková J, Děd J, Bartuška P, Drahokoupil J, Čerňanský M, Lejček P. Analysis of grain boundaries in an embrittled ancient silver necklace. Surf Interface Anal. 2008:40:454-7.

8. Wanhill RJH. Significance of discontinuous precipitation of copper in ancient silver. Metallogr Microstruct Anal. 2012;1:261-8.

9. Doménech A, Doménech-Carbó MT, Pasies T, del Carmen BM. Modeling corrosion of archaeological silver-copper coins using the voltammetry of immobilized particles. Electroanalysis. 2012;24:1945-55.

10. Liu S, Shi M, Zhou Y, Li R, Xie Z, Hu D, Zhang M, Hu G. Scanning electrochemical cell microscopy: a powerful method to study the intergranula corrosions of archaeological silver artifacts. J Cult Herit. 2020;46:176-83.

11. Wanhill RJH. Corrosion-induced embrittlement of ancient silver. Amsterdam: National Aerospace Laboratory NLR; 2002.

12. Evesque $M$, Keddam $M$, Takenouti $H$. The formation of self-assembling membrane of hexadecane-thiol on silver to prevent the tarnishing. Electrochim Acta. 2004;49:2937-43.

13. Mohtat N, Byloos M, Soucy M, Morin S, Morin M. Electrochemical evidence of the adsorption of alkanethiols on two sites on $\mathrm{Ag}(111)$. J Electroanal Chem (Lausanne, Switzerland). 2000;484:120-30.

14. Burleigh TD, Shi C, Kilic S, Kovacik S, Thompson T, Enick RM. Selfassembled monolayers of perfluoroalkyl amideethanethiols, fluoroalkylthiols, and alkylthiols for the prevention of silver tarnish. Corrosion. 2002;58:49-56.

15. Liang C, Yang C, Huang N. Tarnish protection of silver by octadecanethiol self-assembled monolayers prepared in aqueous micellar solution. Surf Coat Technol. 2009;203:1034-44.

16. McEwan JJ, Scott M, Goodwin FE. The optimisation of hexadecanethiol coatings to improve the tarnish resistance of sterling silver. Guangdong: Proceedings 5th Annual China International Silver Conference; 2006

17. Bernard MC, Dauvergne E, Evesque M, Keddam M, Takenouti H. Reduction of silver tarnishing and protection against subsequent corrosion. Corros Sci. 2005;47:663-79.

18. Wang $D$, Li S, Ying Y, Wang M, Xiao H, Chen Z. Theoretical and experimental studies of structure and inhibition efficiency of imidazoline derivatives. Corros Sci. 1999:41:1911-9.

19. Porcinai S, Ferretti M. X-ray fluorescence-based methods to measure the thickness of protective organic coatings on ancient silver artefacts. Spectrochim Acta, Part B. 2018;149:184-9.

20. Frey T, Kögel M. Tarnish protection of silver jewels by plasmapolymer coatings. Surf Coat Technol. 2003;174:902-4.

21. Jordan J, Jacob Kl, Tannenbaum R, Sharaf MA, Jasiuk I. Experimental trends in polymer nanocomposites-a review. Mater Sci Eng. 2005;393:1-11.

22. Zhou B, Peng W. Tusi Cemetery of the Yang Family at Xinpu Town, Zunyi City, Guizhou Province. Archaeology. 2015;7:87-100.

23. Huang Q. Sixteen silver artifacts of Song Dynasty unearthed in Zunyi City have been restored. http://www.kxtwz.com/system/2018/07/03/01667 3608.shtml (accessed December 17, 2021).

24. Xu J. Jinhua Museum: Four years of restoration, a group of unearthed gold and silver artifacts regained their luster. http://wwj.zj.gov.cn/art/ 2021/3/1/art_1641248_58875336.html (accessed December 17, 2021).

25. Yao B, Zhou Z, Duan L, Chen Z. Characterization of three-point bending properties of metal-resin interpenetrating phase composites. RSC Adv. 2018:8:16171-7.

26. Xue X, Liao J, Vincze G, Pereira AB, Barlat F. Experimental assessment of nonlinear elastic behaviour of dual-phase steels and application to springback prediction. Int J Mech Sci. 2016;117:1-15.

27. Insabralde NM, Poletti T, Conti AC, Oltramari-Navarro PV, Lopes MB, FloresMir C, et al. Comparison of mechanical properties of beta-titanium wires between leveled and unleveled brackets: an in vitro study. Prog Orthod. 2014;15:1-7.

28. Zhou T, Nie P, Lv H, Chen Q, Cai X. Assessment of elastic properties of coatings by three-point bending and nanoindentation. J Coat Technol Res. 2011:8:355-61.

29. Abu-Dheir N, Yilbas BS. Laser welding of steel laminates: measurement of elastic modulus with three-point bending. Lasers Eng. 2013;26:231-41.

30. Zhang H, Li Q, Wang Y, Addae M, Jibrin BT, Yang J. Mechanical properties of zinc-aluminum film on steel cable substrate in corrosion environment. J Constr Steel Res. 2018;150:288-97.

31. Maruda RW, Krolczyk GM, Michalski M, Nieslony P, Wojciechowski S. Structural and microhardness changes after turning of the AISI 1045 steel for minimum quantity cooling lubrication. J Mater Eng Perform. 2017;26:431-8.

32. Bartkowska A, Bartkowski D, Swadźba R, Przestacki D, Miklaszewski A. Microstructure, chemical composition, wear, and corrosion resistance of $\mathrm{FeB}-\mathrm{Fe}_{2} \mathrm{~B}-\mathrm{Fe}_{3} \mathrm{~B}$ surface layers produced on Vanadis- 6 steel using $\mathrm{CO}_{2}$ laser. Int J Adv Manuf Technol. 2018;95:1763-76.

33. Ved MV, Sakhnenko MD, Karakurkchi HV, Ermolenko IY, Fomina LP. Functional properties of $\mathrm{Fe}-\mathrm{Mo}$ and $\mathrm{Fe}-\mathrm{Mo}-\mathrm{W}$ Galvanic alloys. Mater Sci. 2016;51:701-10.

34. Béres $G$, Weltsch Z. Estimation of strength properties from microhardness results in dual phase steels with different martensite volume fraction. Period Polytech Transp Eng. 2018;47:206-12.

35. Krolczyk G, Nieslony P, Legutko S. Microhardness and surface integrity in turning process of duplex stainless steel (DSS) for different cutting conditions. J Mater Eng Perform. 2016;23:859-66.

36. Mariani FE, Takeya HS, Lombardi AN, Picone CA, Casteletti LC. Wear and corrosion resistance of $\mathrm{Nb}-\mathrm{V}$ carbide layers produced in vermicular cast iron using TRD treatments. Surface Coatings Technol. 2020;397:126050.

37. Schweizer F, Meyers P. A new approach to the authenticity of ancient silver objects: the discontinuous precipitation of copper from a silvercopper alloy. Zagreb: Rheinland-Verlag GmbH; 1978.

\section{Publisher's Note}

Springer Nature remains neutral with regard to jurisdictional claims in published maps and institutional affiliations.

\section{Submit your manuscript to a SpringerOpen ${ }^{\circ}$ journal and benefit from:}

- Convenient online submission

- Rigorous peer review

- Open access: articles freely available online

- High visibility within the field

- Retaining the copyright to your article

Submit your next manuscript at $\boldsymbol{\nabla}$ springeropen.com 